\title{
Emotion regulation and attachment: Relationships with children's secure base, during different situational and social contexts in naturalistic settings
}

\author{
Lisa Roque*, Manuela Veríssimo, Marília Fernandes, Ana Rebelo \\ UIPCDE, Unidade de Investigação em Psicologia Cognitiva, do Desenvolvimento e da Educação, ISPA - Instituto Universitário, Lisboa, \\ Portugal
}

\section{A R T I C L E I N F O}

\section{Article history:}

Received 7 March 2012

Received in revised form

19 November 2012

Accepted 7 March 2013

Available online 29 March 2013

\section{Keywords:}

Attachment

Emotion regulation

Behavioral strategies

Emotional expressiveness

\begin{abstract}
A B S T R A C T
This study investigated the relationships between children's secure base and emotion regulation, namely their behavioral strategies and emotional expressiveness, during different situational and social contexts in naturalistic settings. Fifty-five children ranging in age from 18 to 26 months of age and their mothers participated in this study. Children were exposed to three situational (fear, positive affect and frustration/anger) and two social (maternal constraint and involvement) contexts. Toddlers' behavioral strategies differed as function of emotion-eliciting context, maternal involvement and attachment quality. Emotional expressiveness varied as function of an interaction involving situational contexts, maternal involvement and children's attachment security.
\end{abstract}

(c) 2013 Elsevier Inc. All rights reserved.

\section{Introduction}

Regulating emotions means having access to a greater number of adaptive strategic behaviors and promoting appropriate and flexible responses in different emotional contexts (Gross \& Thompson, 2007). On the other hand, emotion dysregulation results in having fewer regulatory strategies and the inability to make decisions regarding appropriate conduct in multiple situations (Denham, 1998; Fox, 1994), being related with psychopathological symptoms or deviant developmental trajectories in childhood and adolescence (Maughan \& Cicchetti, 2002). According to a functionalist perspective (Campos, Mumme, Kermoian, \& Campos, 1994), emotion regulation is a dynamical system which main purpose is to accomplish one's immediate or long-term goals. Different emotional contexts have different goals and, therefore, different strategies should be used by children, namely, through the mothers' involvement. For example, increasing avoidance behaviors may help children to regulate themselves during fear episodes, but it does not decrease their distress levels during frustration/anger episodes (Buss \& Goldsmith, 1998; Diener \& Mangelsdorf, 1999a). In this sense, no behavioral strategy is better than the other, it all depends on the context and the individual's (e.g., children) objectives. Therefore it is important to look at children's regulatory strategies' total frequency during different social (e.g., mother constraint and involvement) and situational (e.g., fear, positive affect and frustration/anger) contexts, rather than examining differences in frequencies between specific strategies (Diener \& Mangelsdorf, 1999a; Roque \& Veríssimo, 2011).

\footnotetext{
* Corresponding author at: ISPA - Instituto Universitário, Rua Jardim do Tabaco 34, 1149-041 Lisboa, Portugal.

E-mail address: lisa.roque.psychologist@gmail.com (L. Roque).
} 


\section{Emotion regulation as a dyadic process}

During the first years of life, emotion regulation is a dyadic process, where maternal involvement has a primary role (Sroufe, 1996; Thompson, 1994; Thompson \& Meyer, 2007). At the end of the first year, external support from caregivers is fundamental, as children start to understand the causes of emotional distress and learn to associate caregivers with the possibility to change their negative states and facilitate the implement of effective behavioral strategies (Kopp, 1989). Children between 18 and 24 months, show different behavioral strategies as a function of maternal involvement, in situations of fear and anger. They engage, social reference their mothers and play with stimuli more frequently during mother involved periods, than during constrained ones (Diener \& Mangelsdorf, 1999a). They exhibit behavioral strategies significantly more often during positive affect and anger episodes and fewer during fear episodes (Roque \& Veríssimo, 2011). When it comes to emotional expressiveness, toddlers' exhibit negative and positive emotional expressions, significantly more often during fear and frustration anger episodes and fewer during positive affect episodes (Roque \& Veríssimo, 2011), and express more positive affect than negative affect during mother involved periods, than during constrained ones (Diener \& Mangelsdorf, 1999a).

\section{Emotion regulation and attachment quality}

Research also suggests that the quality of the attachment relationship, influences children's emotion regulation, through the child's expectations (internal working models) about the caregiver's behavior and availability, either physical or emotional (Bowlby, 1969/1982). The attachment figure helps the child to decrease the level of distress by holding, cuddling and talking, or to increase the baby's arousal/tension during a playful game, in order to make the activity more enjoyable and appealing to the child (Sroufe, 1996). Attachment security does not mean denial of negative affect. Instead, it is characterized by the flexibility to integrate positive and negative emotions and the increasing ability to experience and tolerate temporarily threatening and frustrating events, until the child is able to overcome them through long periods of time, even in the absence of the caregiver (Bowlby, 1969/1982, 1980, 1973; Cassidy, 1994, 2008). In case of distress and negative affect episodes, the emotion regulation strategy generally used by secure children involves open, direct and active expression to the mother, instead of hiding negativity from the parent. If the experience allows the feeling of positive emotions, mutual expressions of joy serve to maintain interest in the relationship (Bowlby, 1969/1982; Bretherton, 1990). From an attachment point of view, this flexibility is built over the years, from experiences with a sensitive caregiver, who responds accordingly to the child's needs and emotional signals much of the time and does not ignore any selected behaviors (Bowlby, 1969/1982; Bretherton, 1990).

On the other hand, insecure children, either show minimizing or heightening emotion expressiveness (Bretherton, 1990; Cassidy, 1994). Insecure children who show a suppression of emotional expression seem to be neutral, showing less negative vocalizations during separations or pleasure on reunions, than secure children, exhibiting, preferably, self-oriented emotion regulation behavioral strategies, instead of mother-oriented strategies (Braungart \& Stifer, 1991; Cassidy, 1994; Spangler \& Grossmann, 1993). From an attachment point of view, minimizing distress, fear, sadness or anger, may have an adaptive effect, by reducing rejection experiences and maintaining sufficient proximity toward the parents, in order to guarantee protection (Bowlby, 1973, 1980). However, minimizing negative effect may be maladaptive in other social or problem-solving contexts, where certain emotion displays are expected.

On the other hand, insecure children can also show a pattern of emotional expression and regulation characterized by heightened negative emotionality and exaggerated fearfulness toward non-threatening stimuli. This behavioral pattern may also be an adaptive strategy used to increase the probability of gaining the attention of an insufficiently or inconsistently available parent if true danger appears (Main, Kaplan, \& Cassidy, 1985; Main, 2000). However, this emotion regulation strategy may become maladaptive if it interferes with exploration or threatens the existence of the attachment relationship (Bowlby, 1973, 1980).

\section{Aims of the study}

The objective of this work was to study the relationships between children's attachment (secure base phenomenon) and emotion regulation (behavioral strategies and emotional expressiveness), during different social (mother constrained and involved periods) and situational (fear, positive affect and frustration/anger) contexts. We expected that: (1) secure children would show behavioral strategies more frequently, during mother involved periods, than during constrained ones in all three episodes, using the caregiver as a "safe haven", where protection and comfort can be found during negative affect episodes (Bowlby, 1969/1982) and as a way of making positive affect episodes more enjoyable and appealing, by increasing arousal and mutual expressions of joy (Bretherton, 1990; Sroufe, 1996). On the other hand, insecure children would show no significant differences between mother constrained and involved periods in the frequency of behavioral strategies used during the three episodes, since they exhibit, preferably, self-oriented emotion regulation behavioral strategies, instead of motheroriented strategies (Braungart \& Stifer, 1991; Cassidy, 1994; Spangler \& Grossmann, 1993); (2) secure children would show behavioral regulatory strategies more frequently, than insecure ones during negative (fear; frustration/anger) and positive affect episodes, since secure attachment is associated with open, direct and active expression to the mother, instead of hiding negativity from the parent, during stressful and positive affect situations (Bowlby, 1969/1982; Bretherton, 1990); 
(3) secure children would show emotional expressions (positive and negative) significantly more often during mother's involved periods, than constrained ones during the three episodes, since a sensitive and ameliorative response is expected by the attachment figure (Bretherton, 1990; Cassidy, 1994; Gross \& Thompson, 2007). On the other hand, insecure children would show no significant differences in their emotional expressions, between mother constrained and involved periods, during the three episodes, since an ameliorative response is not expected by the attachment figure; (4) insecurely attached children would show minimizing or heightening emotion expressiveness in terms of frequency of emotional expressions, when compared to securely attached ones (Malatesta, Culver, Tesman, \& Shepard, 1989; Main, 2000), during the three episodes.

\section{Methods}

\subsection{Participants}

Fifty-five child-mother dyads ( 27 boys and 28 girls), all Caucasian, from bi-parental families participated in the study. Children's age ranged from 18 to 26 months of age $(M=21.35 ; S D=1.91)$. Twenty-seven were firstborn and 28 had siblings. They started attending day-care between 6 and 24 months $(M=7.53 ; S D=4.81)$ and spent $7-11 \mathrm{~h}(M=6.96 ; S D=2.64)$ at day-care each weekday. Mothers' age ranged from 25 to 43 years $(M=33.64 ; S D=4.10)$ and fathers' age from 26 to 55 years old $(M=35.71 ; S D=5.73)$. Mothers' level of education ranged from 5 to 19 years $(M=14.87 ; S D=3.38)$ and fathers' from 4 to 19 years $(M=13.71 ; S D=3.60)$. Participants represented a range of socioeconomic status backgrounds, as reflected by parental education and were recruited from public and private day-care centers. All participants were healthy at the time of assessment and there were no premature children.

\subsection{Measures}

This research was conducted in accordance with APA ethical standards in the treatment of the study sample.

\subsubsection{Emotion regulation paradigm: fear, positive affect, frustration/anger}

The emotion regulation paradigm (Diener \& Mangelsdorf, 1999a), measured the behavioral strategies and emotional expressiveness exhibited by children during three episodes: positive affect, fear and frustration/anger, elicited by the presentation of three different toys. Each episode lasted for $6 \mathrm{~min}$ and had two distinct moments which lasted 3 min each: (1) mother constrained period (mothers were instructed to refrain from initiating interaction with their children. If their children made bids for attention, mothers were instructed to respond to them with brief statements about the stimuli presented in each episode: "It's the dinosaur/piano/bear"); (2) mother involved period (mothers were instructed to be at ease with the child and the toy. Free behavior was allowed, whatever they felt it was appropriate, according to their sensitivity).

5.2.1.1. Emotional stimuli. All stimuli used in this work were previously tested in a pilot test, which showed a varying emotional intensity in most children. During the frustration/anger episode, we presented children with a movable box with wheels, shaped in the form of a yellow bear, which contained colored lego pieces inside. After the experimenter felt that the child was involved with the toy ( 2 min on average), the experimenter took the toy away firmly and placed it out of reach but within the child's sight. During fear episodes, a dinosaur toy with elements of novelty, unpredictability and intrusiveness was used to elicit fear. Finally, during the positive affect episode, children were given a toy piano that played music and created musical rhythms. Similar procedures and toys were used in other studies (Buss \& Goldsmith, 1998; Diener \& Mangelsdorf, 1999a; Grolnick, Bridges, \& Connell, 1996). The emotion regulation episodes were videotaped in different days, usually during a period of two weeks, with a minimum of two days apart, from each session, in order to avoid any emotional contamination from one episode to the other and to guarantee that each episode only aroused one emotion at the time. They all started at the same time (18 h 30). The time chosen to start the experiments was late afternoon, because $96 \%$ of the mothers worked outside the home and finish their shift around $17 \mathrm{~h} 00$. The episodes were videotaped at the family's house, always in the same room, the living room, because it present itself as the most spacious and neutral place of the house, without any other toys that could serve as a distraction from the stimuli. All the electric devices present (television set) were turned off during the sessions and only the child, the mother and two experimenters were present in the room. The stimuli were placed in the center of the room, to allow children to explore freely. The three episodes were counter-balanced across subjects in order to control any order effect over the results. Previous work has shown that the emotional manipulations were effective, i.e., the target emotion was expressed more frequently in the correspondent episode, than the other emotions in a significant way (Diener \& Mangelsdorf, 1999a; Roque \& Veríssimo, 2011).

5.2.1.2. Children behavioral strategies. Nineteen behavioral strategies were coded (see Diener \& Mangelsdorf, 1999a,b): proximity/contact seeking to mother; directing mother; fuss to mother; help seeking; information seeking; social referencing/looks to mother; engagement of mother; passive disengagement; distraction toward other object; leavetaking; 
avoidance; playing/exploring; resistance/control; labeling; problem solving; proximity to stimulus; tension release; selfsoothing. During the course of our study, another set of behaviors was observed, besides the ones proposed by Diener and Mangelsdorf (1999a,b). This one was coded under the name of "stranger", because it was characterized by behaviors directed at the strangers (experimenters) in the room during the sessions.

Children's behavioral strategies were coded dichotomously on an occurrence/non occurrence way, in 15 s intervals ( 1 occurrence; 0 - non occurrence). Each 3 min period had twelve $15 \mathrm{~s}$ intervals. The results for each strategy were summed for a total score. The possible range for each behavior was $0-12$, for each $3 \mathrm{~min}$ period. If an episode was terminated because of child distress, scores were prorated on the basis of the number of intervals completed, by dividing the sums of the scores by the number of intervals completed and multiplying 12 (the total number of intervals possible) (Diener \& Mangelsdorf, 1999a).

5.2.1.3. Emotional expression. The predominant emotion showed by children during the three episodes was also coded. Fear was scored when the child expressed at least one of these facial features: eyebrows raised or drawn together; eyes wide; mouth open, corners straight back. Positive affect was scored when the child smiled or produced a positive vocalization (laugh). Anger was coded when the child showed at least one of the following: brows pulled back down or together; raised cheeks; straight or angular mouth or tight lips. A score of "neutral" was given when the child did not express any of these emotions and showed a neutral expression. Neutral scores were not included in the analysis. The child's quality of emotion (positive; anger/frustration; fear; neutral) was coded during the $15 \mathrm{~s}$ intervals. If the child expressed more than one emotion during the time intervals used for coding, the most intense emotion was coded as the predominant one in a scale of 1 (mild intensity) to 3 (extremely intense) for each 15-s interval. Extremely intense emotion could be expressed by facial affect, body postures, gestures and movements or full intensity vocalizations (e.g., laughter for positive affect; crying or screaming for negative affect). Low intensity affect seemed mild and would be more ambiguous than high intensity one. To obtain emotional expression scores we added the number of 15-s intervals each child expressed fear, frustration/anger and positive affect as the predominant emotion (Diener \& Mangelsdorf, 1999a).

Separate pairs of coders, blinded to the hypotheses, coded the three episodes. Inter-rater reliability was calculated using Cohen's Kappas for behavioral strategies (fear $=0.73$; positive affect $=0.84$; frustration/anger $=0.70$ ) and emotional expressions (fear $=0.70$; positive affect $=0.80$; frustration/anger $=0.78$ ). This coding system is similar to those used in other studies of children coping strategies (Buss \& Goldsmith, 1998; Calkins \& Johnson, 1998; Diener \& Mangelsdorf, 1999a; Parritz, 1996).

\subsubsection{Attachment behavior Q-set (AQS) (version 3.0)}

The Attachment Behavior Q-set (AQS) (Waters, 1995) assesses the quality of the child's secure base behavior toward the mother or other figures in an ecologically valid context, namely, the children's home, during a period of $2 \mathrm{~h}$. The 90 items of this instrument are distributed on a scale of 9 points, ranging from "extremely characteristic" to "extremely uncharacteristic". Mothers became aware of this work through an informed consent, left at their children's daycare. The AQS home visits were scheduled with the mother in a time of day when any other members of the family or friends were present at home. The visits were conducted by two observers that were trained not to disturb interactions in progress or interfere in domestic routines. The observers' agreement was analyzed through Spearman Brown correlations $(M=0.80)$. Individual Q-sorts, resulted from a mean between the descriptions of the two observers. Children's final attachment score was obtained through a Pearson correlation between the child's individual Q-sort and the security criterion value of the "ideal child" (Waters, 1995; Waters \& Deane, 1985). This correlation represents the place occupied by children on a security continuum. This value ranges between -1.0 and 1.0. Children who are able to use the mother or other figure as a secure base receive a higher value, while the least able to do it, receive lower values. In most normative samples, security scores average about 0.35 (Bost, 2006). This study uses the AQS for child attachment, instead of the Strange Situation (Ainsworth, Blehar, Waters, \& Wall, 1978) procedure. Both measures are used in the field and both have proved to be valid measures to access quality of attachment. The validity of the AQS using observers, but not self-reported, has been clearly confirmed in a meta-analysis (van IJzendoorn, Vereijken, Bakermans-Kranenburg, \& Riksen-Walraven, 2004) and it was included in the same category, in terms of quality, as that of the Strange Situation. Previous studies with Portuguese samples supported the utility and validity of the AQS in the Portuguese culture (Veríssimo, Monteiro, Vaughn, Santos, \& Waters, 2005; Veríssimo, Monteiro, \& Santos, 2006). Also, and very important, the Strange Situation is not recommended for the age level of our participants (Ainsworth et al., 1978).

\section{Results}

\subsection{Preliminary analyses}

No significant child gender differences were found in child attachment $(M$ boys $=0.43, S D=0.26 ; M$ girls $=0.49, S D=0.27$; $t(53)=0.78, p>0.05)$ and in emotion regulation strategies $(F(1,53)=0.00, p>0.05)$.

\subsection{Relationships between children's attachment (AQS) and emotion regulation behavioral strategies}

Children's 19 behavioral strategies during mother constrained and involved periods, in episodes of fear, positive affect and frustration/anger were the dependent variables, and children's attachment was the independent variable. A repeated 
Table 1

Means and standard errors for children's emotion regulation behavioral strategies, as function of children's attachment security, maternal behavior and episode.

\begin{tabular}{|c|c|c|c|c|}
\hline Children's attachment & Episode & Mothers' condition & $M$ & $S E$ \\
\hline \multirow[t]{6}{*}{ Secure $(n=40)$} & \multirow[t]{2}{*}{ Fear } & Constrained & 1.82 & 0.10 \\
\hline & & Involved & 2.34 & 0.08 \\
\hline & \multirow[t]{2}{*}{ Positive affect } & Constrained & 2.78 & 0.08 \\
\hline & & Involved & 3.00 & 0.08 \\
\hline & \multirow{2}{*}{ Frustration/anger } & Constrained & 2.64 & 0.13 \\
\hline & & Involved & 2.74 & 0.11 \\
\hline \multirow[t]{6}{*}{ Insecure $(n=15)$} & \multirow[t]{2}{*}{ Fear } & Constrained & 1.76 & 0.16 \\
\hline & & Involved & 2.23 & 0.13 \\
\hline & \multirow[t]{2}{*}{ Positive affect } & Constrained & 2.58 & 0.13 \\
\hline & & Involved & 2.57 & 0.14 \\
\hline & \multirow[t]{2}{*}{ Frustration/anger } & Constrained & 2.34 & 0.22 \\
\hline & & Involved & 2.96 & 0.18 \\
\hline
\end{tabular}

measures MANOVA was undertaken and three within-subject effects levels were used: episode (fear, positive affect, and frustration/anger); maternal condition (constrained and involved) and 19 emotion regulation behavioral strategies. For use as a between-subjects factor, children's attachment security (AQS) was dichotomized. The participants were grouped according to their scores on the AQS, into participants with secure (score $\geq 0.35)$ vs. insecure $($ score $<0.35)$ attachment (Bost, 2006). Results revealed significant main effects for episode $(F(2,106)=26.38, p<0.001)$; maternal condition $(F(1$, $53)=25.56, p<0.001)$ and behavioral strategies $(F(18,954)=129.18, p<0.001)$. Most importantly, a significant interaction episode $\mathrm{x}$ maternal condition $\times$ attachment was found $(F(2,106)=3.70, p<0.05)$.

Planned contrast estimates analyses revealed that during fear episodes, children with secure attachment (see Table 1), showed behavioral strategies significantly more often during mother involved periods, than during mother constrained ones $(t(53)=5.11, p<0.001)$. During positive affect episodes, secure children also exhibited behavioral strategies significantly more often when their mothers behavior was involved, than when it was constrained $(t(53)=2.41, p<0.05)$. During frustration/anger episodes, secure children did not show significant differences between mother constrained and involved periods. During mother constrained periods, secure children (see Table 1 ) engaged in behavioral strategies significantly more often during frustration/anger and positive affect episodes, than during fear episodes $(t(53)=5.49, p<0.001 ; t(53)=8.32, p<0.001$, respectively). No significant differences were found between frustration/anger and positive affect episodes. During mother involved periods, secure children (see Table 2 ) exhibited behavioral strategies significantly more often during positive affect and frustration/anger episodes, than during fear situations $(t(53)=6.65, p<0.001 ; t(51)=2.71, p=0.01$, respectively).

Table 2

Means and standard errors for children's emotional expressions, as function of children's attachment security, maternal condition and episode.

\begin{tabular}{|c|c|c|c|c|c|c|}
\hline \multirow[t]{3}{*}{ Children's attachment } & \multirow[t]{3}{*}{ Episode } & \multirow[t]{3}{*}{ Children's emotional expression } & \multicolumn{4}{|c|}{ Mothers' condition } \\
\hline & & & \multicolumn{2}{|c|}{ Constrained } & \multicolumn{2}{|c|}{ Involved } \\
\hline & & & $M$ & $S E$ & $M$ & $S E$ \\
\hline \multirow{12}{*}{ Secure $(n=40)$} & \multirow[t]{4}{*}{ Fear } & Positive & 3.07 & 0.74 & 4.66 & 0.77 \\
\hline & & Frustration/anger & 0.13 & 0.12 & 0.48 & 0.19 \\
\hline & & Fear & 7.04 & 0.82 & 6.19 & 0.74 \\
\hline & & Total & 3.41 & 0.20 & 3.78 & 0.13 \\
\hline & \multirow[t]{4}{*}{ Positive affect } & Positive & 3.42 & 0.66 & 5.64 & 0.66 \\
\hline & & Frustration/anger & 0.33 & 0.15 & 0.92 & 0.36 \\
\hline & & Fear & 1.35 & 0.42 & 0.47 & 0.23 \\
\hline & & Total & 1.70 & 0.21 & 2.34 & 0.21 \\
\hline & \multirow[t]{4}{*}{ Frustration/anger } & Positive & 1.18 & 0.30 & 3.43 & 0.55 \\
\hline & & Frustration/anger & 8.66 & 0.56 & 3.49 & 0.48 \\
\hline & & Fear & 0.00 & 0.00 & 0.00 & 0.00 \\
\hline & & Total & 3.28 & 0.15 & 2.31 & 0.18 \\
\hline \multirow[t]{12}{*}{ Insecure $(n=15)$} & \multirow[t]{4}{*}{ Fear } & Positive & 3.87 & 1.21 & 4.13 & 1.25 \\
\hline & & Frustration/anger & 0.40 & 0.20 & 0.13 & 0.31 \\
\hline & & Fear & 5.67 & 1.35 & 6.82 & 1.21 \\
\hline & & Total & 3.31 & 0.32 & 3.69 & 0.21 \\
\hline & \multirow[t]{4}{*}{ Positive affect } & Positive & 5.79 & 1.08 & 6.29 & 1.08 \\
\hline & & Frustration/anger & 0.33 & 0.25 & 1.53 & 0.58 \\
\hline & & Fear & 1.13 & 0.68 & 0.00 & 0.00 \\
\hline & & Total & 2.42 & 0.35 & 2.61 & 0.33 \\
\hline & \multirow[t]{4}{*}{ Frustration/anger } & Positive & 0.00 & 0.00 & 4.60 & 0.89 \\
\hline & & Frustration/anger & 10.00 & 0.91 & 2.49 & 0.79 \\
\hline & & Fear & 0.00 & 0.00 & 0.00 & 0.00 \\
\hline & & Total & 3.33 & 0.25 & 2.36 & 0.29 \\
\hline
\end{tabular}


On the other hand, insecure children, during fear episodes (see Table 1 ) showed behavioral strategies significantly more often during mother involved periods, than during mother constrained ones $(t(53)=2.68, p=0.01)$. During frustration/anger episodes, insecure children also exhibited behavioral strategies significantly more often when the mothers' behavior was involved, than when it was constrained $(t(53)=2.97, p<0.01)$. No significant differences were found for positive affect episodes. During mother constrained periods, insecure children (see Table 1) engaged in behavioral strategies significantly more often during positive affect and frustration/anger episodes, than during fear episodes $(t(53)=4.38, p<0.001$; $t(53)=2.40, p<0.05$, respectively). No significant differences were found between frustration/anger and positive affect episodes. During mother involved periods, insecure children (see Table 1) exhibited behavioral strategies significantly more often during frustration/anger and positive affect episodes, than during fear ones $(t(53)=3.23, p<0.01 ; t(53)=2.22, p<0.05$, respectively).

No significant differences were found between secure and insecure children, either in fear, positive affect or frustration/anger episodes, during mother constrained periods (see Table 1). On the other hand, during mother involved periods (see Table 1), secure children showed strategies significantly more often, than insecure ones, during positive affect episodes $(t(53)=2.65, p=0.01)$. No significant differences were found for fear or frustration/anger episodes.

\subsection{Relationships between children's attachment (AQS) and children's emotional expressiveness}

Children's emotional expressions of fear, positive affect and frustration/anger during mother constrained and involved periods, in the three episodes were the dependent variables, and children's attachment was the independent variable. A repeated measures MANOVA was undertaken and three within-subject effects levels were used: episode; emotional expressions (fear, positive affect and frustration/anger) and maternal condition. Children's attachment security (AQS) was used as between-subject effects factor. Results showed significant main effects for emotional expressions $(F(2,106)=7.02$, $p=0.01)$ and episode $(F(2,106)=24.44, p<0.001)$. Most importantly, a significant interaction episode $\times$ maternal condition $\times$ emotional expressions $\times$ children's attachment security was found $(F(4,212)=3.30, p=0.01)$.

Planned contrast estimates analyses revealed that during fear episodes, secure children (see Table 2 ) showed positive affect expressions significantly more often during mother involved periods, than during constrained ones $(t(53)=2.45$, $p<0.05$ ). No significant differences in frustration/anger or fear expressions were found between the two periods.

During positive affect episodes, secure children (see Table 2 ) showed positive affect expressions significantly more often when the mothers' behavior was involved, than when it was constrained $(t(53)=4.01, p<0.01)$. They expressed fear significantly more often during mother constrained periods, than during mother involved ones $(t(53)=2.41, p<0.05)$. No significant differences between the two periods were found for frustration/anger expressions. In total, during positive affect episodes, secure children (see Table 2 ) exhibited emotional expressiveness significantly more often during mother involved periods, than during mother constrained ones $(t(53)=2.89, p<0.01)$.

During frustration/anger episodes, secure children (see Table 2) exhibited positive affect expressions significantly more often when the mothers' behavior was involved, than when it was constrained $(t(53)=3.59, p=0.01)$. They showed frustration/anger expressions significantly more often during mother constrained periods, than during mother involved ones $(t$ $(53)=7.02, p<0.001$ ). In total, during frustration/anger episodes, secure children (see Table 2 ) exhibited emotional expressions significantly more often during mother constrained periods, than during the mother involved periods $(t(53)=4.61$, $p<0.001$ ).

On the other hand, insecure children (see Table 2), did not show any significant differences in their emotional expressions between mother constrained and involved periods, either during fear or positive affect episodes. During frustration/anger episodes (see Table 2), insecure children expressed positive affect expressions significantly more often during mother involved periods, than during mother constrained ones $(t(53)=4.48, p<0.001)$. They also expressed frustration/anger expressions significantly more often when the mothers' behavior was constrained, than when it was involved $(t(53)=6.25$, $p<0.001$ ). No significant differences between the two periods were found for fear expressions.

\section{Discussion}

Toddlers' behavioral strategies differed as a function of situational (episodes), and social (maternal involvement) contexts but, most importantly, as a function of an interaction involving children's attachment quality. When it comes to maternal involvement, during fear episodes, both secure and insecure children increased their behavioral strategies' frequency when their mothers were involved. This finding is consistent with Bowlby's (1969/1982) perspective. According to the author, proximity behaviors and physical contact with the attachment figure are exhibited, particularly, during stressful or dangerous situations, when the caregiver is used as a "safe haven", where protection and comfort can be found (Ainsworth, 1967; Ainsworth et al., 1978; Bowlby, 1969/1982). During positive affect contexts, when the possibility for increasing emotional proximity to the mother through play is possible, only secure children, not insecure ones, showed behavioral strategies significantly more often when the mothers' behavior was involved. During frustration/anger contexts, when children's gratification is delayed and dependent on the mothers' involvement, secure children showed no significant differences between the constrained and involved periods. This might have happened due to the existence of a positive working model of the attachment figure in secure children, based on past experiences during which the mothers' active participation and intervention was beneficial and 
helped children to regulate their emotions and accomplish their goals (Ainsworth et al., 1978; Bowlby, 1973, 1980; Waters, Vaughn, Posada, \& Kondo-Ikemura, 1995). On the opposite, insecure children have not developed an internal working model based on the mothers' sensitive help and, therefore, must increase their strategies to call the caregivers' attention to their needs when they became involved (Ainsworth et al., 1978; Bowlby, 1973, 1980; Waters et al., 1995).

When it comes to situational contexts, both secure and insecure children engaged in behavioral strategies significantly more often during frustration/anger and positive affect episodes, than during fearful ones, both when their mothers' behavior was constrained or involved. In both positive affect and frustration/anger episodes, the stimuli were desirable objects to play (a piano with musical sounds and legos, respectively), which promoted approach behaviors. It might have been that the desire to play with the stimulus during the positive affect episodes and the motivation to obtain the object during the frustration/anger situations, made children try more behavioral strategies in order to accomplish their immediate goals and regulate themselves. On the other hand, during fear episodes, children exhibited behavioral strategies, significantly less often, probably because the stimulus was too threatening to promote any approach behaviors. Finally, securely attached children exhibited behavioral strategies significantly more often during positive affect contexts, than insecurely attached ones, only when the mothers' behavior was involved. No significant differences were found for fear or frustration/anger episodes, which suggests that secure children only exhibit more behavioral strategies than insecure ones, during specific contexts and not in all, as it was expected. During negative emotional contexts, secure and insecure children seemed to use the mothers' involvement in the same way, as a "safe haven", where protection for danger (fear episodes) or comfort from distress (frustration/anger episodes) can be found. However, differences emerge in positive affect contexts, where distress is not present, but rather the possibility to increase emotional proximity, through play. This finding is also consistent with Bowlby's work (1969/1982), which postulates that attachment relationship is a regulatory behavioral system characterized not only by a "haven of safety", but also by the formation of a loving bond, characterized by the capacity to seek and sustain emotional proximity by both partners during positive affect emotional contexts. Similar to Diener and Mangelsdorf's work (1999a), the mother constrained and involved periods were not counterbalanced, since during pilot testing, maternal involvement seemed to change children's emotional interpretation of the stimuli, particularly, during fear episodes, which is a limitation in this study.

Children's emotional expressions differed as function of an interaction involving situational context, maternal involvement and children's attachment security. In particular, secure children showed emotional expressions (positive and negative) significantly more often when their mothers' behavior was involved, during positive affect contexts. Secure children might have used emotional expressiveness during mother involved periods, as a way to signal their mothers about their intention to play or approach the toys together and not alone. In fact, secure attachment is characterized by an active participation of both partners during tasks and a desire for emotional proximity (Bowlby, 1969/1982, 1973, 1980). However, during frustration/anger episodes secure children exhibited emotional expressions (positive and negative) significantly more often when the mother was constrained and not involved, probably, because interactive play could only be achieved by first signaling the mothers to get involved and retrieve the toy. This signaling might have been done through emotional expressiveness. In fact, Cassidy (1994), Bretherton (1990) and Stern (1985), mention the use of open, direct and active expression in secure children, as a way to send and receive signals unrestrictedly, instead of hiding it from the parent. This open communication style occurs in secure children because, unlike insecure children, a sensitive and ameliorative response is expected by the attachment figure (Cassidy, 2008). Secure children also showed significantly more positive affect expressions when their mothers' behavior was involved, independently of the emotional context experienced, either positive or negative (fear, frustration/anger episodes). This finding is consistent with Thompson (1994) and Gross and Thompson (2007) perspective, which defends that emotion regulation involves not just the inhibition of negative affect, but also the maintenance and enhancement of positive affect.

On the other hand, insecure children showed no significant differences in their emotional expressions, between mother constrained and involved periods, during fear or positive affect episodes, except during frustration/anger ones. During fear and positive affect contexts, the mothers' involvement seemed indifferent in changing insecure children's emotional expressions. Our results are consistent with Lutkenhaus, Grossmann, and Grossmann (1985); Spangler and Grossmann (1993) and Malatesta et al. (1989), where insecure avoidant children showed a minimizing emotion expression style. In contrast to the Strange Situation procedure, the AQS does not present a differentiation between insecure avoidant and insecure ambivalent children, which is a limitation in this study. In the future it would be interesting to replicate this study using the Strange Situation and compare it with the results of this work. Finally, in frustration/anger contexts, during the mothers' involvement periods, insecure children showed significantly less expressions of frustration/anger and more expressions of positive affect. In this context, insecure children might have perceived mothers' involvement not as a possibility for emotional proximity, but as an instrumental way to achieve their goal and, consequently, reduce their frustration levels.

\subsection{Future research}

In future research it is important to explore possible interactions between attachment and children's internal processes (temperament, biological systems), in the study of emotion regulation during the first years of life. 


\section{Conflict of interest statement}

All authors declare that they have no conflicts of interest.

\section{Acknowledgments}

The authors wish to thank all the children, families and institutions who participate in this study. This work was supported in part by grants from Fundação para a Ciência e Tecnologia (FCT) to I \& D Unit No. 332/94 and SFRH/BD/23365/2005. FCT had no further role in study design; in the collection, analysis and interpretation of data; in the writing of the report and in the decision to submit the paper for publication. We are also grateful to all the colleagues from UIPCDE (Line 1 - Developmental Psychology) for their valuable comments, in particular Filipa Silva, Ligia Monteiro, Nuno Torres, Orlando Santos, Paula Machado and Teresa Rolão for their technical assistance in scoring the data.

\section{References}

Ainsworth, M. D. S. (1967). In infancy in Uganda - Chapter 20. Retrieved from. http://www.psychology.sunysb.edu/attachment/ainsworth/ainsworth_index Ainsworth, M. D. S., Blehar, M., Waters, E., \& Wall, S. (1978). Patterns of attachment: A psychological study of the Strange Situation. Hillsdale, NJ: Erlbaum.

Bost, K. (2006, April). Attachment: AQS methodology. In Workshop presented at the Instituto Superior de Psicologia Aplicada, Lisbon, Portugal.

Bowlby, J. (1973). Attachment and loss: Vol. 2. Separation, anxiety, and anger. New York: Basic.

Bowlby, J. (1980). Attachment and loss: Vol. 3. Loss, sadness and depression. New York: Basic.

Bowlby, J. (1982). Attachment and loss: Vol. 1. Attachment. London: Hogarth Press. (Original work published in 1969).

Braungart, J. M., \& Stifer, C. A. (1991). Regulation of negative reactivity during the Strange Situation: Temperament and attachment in 12-month-old infants. Infant Behavior and Development: 14., 349-367.

Bretherton, I. (1990). Open communication and internal working models: Their role in the development of attachment relationships. In R. A. Thompson (Ed.), Socioemotional development (pp. 57-113). Lincoln: University of Nebraska Press.

Buss, K. A., \& Goldsmith, H. H. (1998). Fear and anger regulation in infancy: Effects on the temporal dynamics of affective expression. Child Development: 69., 359-374.

Calkins, S., \& Johnson, M. (1998). Toddler regulation of distress to frustrating events: Temperamental and maternal correlates. Infant Behavior and Development: 21., (3), 379-395.

Campos, J. J., Mumme, D. L., Kermoian, R. K., \& Campos, R. G. (1994). A functionalist perspective on the nature of emotion. In N. Fox (Ed.), The development of emotion regulation: Biological and behavioral considerations (pp. 284-303). Monographs of the Society for Research on Child Development, 59 (Serial No. 240).

Cassidy, J. (1994). Emotion regulation: Influences of attachment relationships. In N. Fox (Ed.), The development of emotion regulation: Biological and behavioral considerations (pp. 229-249). Monographs of the Society for Research on Child Development Monograph, 59 (Serial No. 240).

Cassidy, J. (2008). The nature of the child's ties. In J. Cassidy, \& P. R. Shaver (Eds.), Handbook of attachment: Theory, research and clinical applications (2nd ed., pp. 3-22). New York: The Guilford Press.

Denham, S. A. (1998). Emotional development in young children. New York, NY: Guildford Press.

Diener, M., \& Mangelsdorf, S. (1999). Behavioral strategies for emotion regulation in toddlers: Associations with maternal involvement and emotional expressions. Infant Behavior and Development: 22., (4), 569-583.

Diener, M., \& Mangelsdorf, S. (1999b). Emotion regulation coding (Unpublished manuscript).

Fox, N. A. (1994). The development of emotion regulation: Biological and behavioral considerations. Monographs of the Society for Research in Child Development: 59. (Serial No. 240).

Grolnick, W. S., Bridges, L. J., \& Connell, J. P. (1996). Emotion regulation in two-year-olds: Strategies and emotional expression in four contexts. Child Development: 67., 928-941.

Gross, J. J., \& Thompson, R. A. (2007). Emotion regulation: Conceptual foundations. In J. J. Gross (Ed.), Handbook of emotion regulation (pp. 3-26). New York: Guilford Press.

Kopp, C. B. (1989). Regulation of distress and negative emotions: A developmental view. Developmental Psychology: 25., (3), 343-354.

Lutkenhaus, P., Grossmann, K. E., \& Grossmann, K. (1985). Infant-mother attachment at 12 months and style of interaction with a stranger at the age of three. Child Development: 56., 1538-1572.

Malatesta, C. Z., Culver, C., Tesman, J. R., \& Shepard, B. (1989). The development of emotion expression during the two first years of life. Monographs of the Society for Research in Child Development: 54., (1-2), 1-104 (Serial No. 219).

Main, M., Kaplan, N., \& Cassidy, J. (1985). Security in infancy, childhood and adulthood: A move to the level of representation. In I. Bretherton, \& E. Waters (Eds.), Growing points of attachment theory and research. Monographs of the Society for Research in Child Development, 50 (1-2) (Serial No. 209).

Main, M. (2000). The organized categories of infant, child, and adult attachment: Flexible vs inflexible attention under attachment-related stress. Journal of American Psychological Association: 48., (4), 1055-1095.

Maughan, A., \& Cicchetti, D. (2002). Impact of child maltreatment and interadult violence on children's emotion regulation abilities and socioemotional adjustment. Child Development: 73., 1525-1542.

Parritz, R. H. (1996). A descriptive analysis of toddler coping in challenging circumstances. Infant Behavior and Development: 19., 171-180.

Roque, L., \& Veríssimo, M. (2011). Emotional context, maternal behavior and emotion regulation. Infant Behavior and Development: $34 ., 617-626$.

Sroufe, L. A. (1996). Emotional development: The organization of emotional life in the early years. New York: Cambridge University Press.

Spangler, G., \& Grossmann, K. E. (1993). Biobehavioral organization in secure and insecurely attached infants. Child Development: 64., 1439-1450.

Stern, D. N. (1985). The interpersonal world of the infant: A view from psychoanalysis and developmental psychology. New York: Basic.

Thompson, R. (1994). Emotion regulation: A theme in search of definition. In N. Fox (Ed.), The development of emotion regulation: Biological and behavioral considerations (pp. 25-52). Monographs for the Society for Research on Child Development, 59 (Serial No. 240).

Thompson, R. A., \& Meyer, S. (2007). Socialization of emotion regulation in the family. In J. J. Gross (Ed.), Handbook of emotion regulation (pp. 3-26). New York: Guilford Press.

van IJzendoorn, M. H., Vereijken, C. M., Bakermans-Kranenburg, M. J., \& Riksen-Walraven, J. M. (2004). Assessing attachment security with the attachment Q-sort: Meta-analytic evidence for the validity of the observer AQS. Child Development: 75., 1188-1213.

Veríssimo, M., Monteiro, L., Vaughn, B. E., Santos, A. J., \& Waters, H. (2005). Coordenação entre o modelo interno dinâmico da mãe e o comportamento de base segura dos seus filhos. Análise Psicológica: 23., (2), 7-17.

Veríssimo, M., Monteiro, L., \& Santos, A. J. (2006). Para além da mãe: Vinculação na tríade mãe-pai-criança. In J. C. Coelho Rosa, \& S. Sousa (Eds.), Caderno do bebé (pp. 73-85). Fim de Século.

Waters, E., \& Deane, K. (1985). Defining and assessing individual differences in attachment relationships: Q-methodology and the organization of behavior in infancy and early childhood. In I. Bretherton \& E. Waters (Eds.), Growing points of attachment theory and research (pp. 41-65). Monographs of the Society for Research in the Child Development, 50 (1-2). 
Waters, E. (1995). Appendix A: Attachment Q-set (version 3.0). In Waters, Vaughn, Posada, \& Kondon-Ikemura (Eds.), Caregiving, cultural, and cognitive perspectives on secure-base behavior and working models: New growing points of attachment theory and research (pp. 234-246), Monographs Child Development, $60(2-3)$

Waters, E., Vaughn, B. E., Posada, G., \& Kondo-Ikemura, K. (Eds.). (1995). Caregiving, cultural, and cognitive perspectives on secure-base behavior and working models: New growing points of attachment theory and research. Monographs of the Society for Research in Child Development: 60., (2-3) (Serial No. 244). 